\title{
Unintentional Extraction of Previously Deployed Stent in Ostial Left Anterior Descending Artery during a Dislodged Left Main Stent Retrieval
}

\author{
Mehmedbegovic $\mathrm{Z}^{1 *}$, Beleslin B1, Dikic $\mathrm{M}^{1}$, Stankovic $\mathrm{G}^{1}$, Vukcevic ${ }^{1}$, Orlic $\mathrm{D}^{1}$, Milasinovic $\mathrm{D}^{1}$, Stojkovic $\mathrm{S}^{1}$, \\ Sagic $D^{2}$ and Ruzicic $D^{3}$ \\ ${ }^{1}$ Clinical Center of Serbia, Cardiology Clinic, Serbia \\ ${ }^{2}$ Institute for Cardiovascular Diseases, Serbia \\ ${ }^{3}$ General Hospital, Serbia
}

Submission: February 06, 2017; Published: March 21, 2017

*Corresponding author: Mehmedbegovic Z, Clinical Center of Serbia, Cardiology Clinic, Pasterova 2, 11000 Belgrade, Serbia,

Tel: +381 6066787 61; Email: zlatkombegovic@gmail.com

\section{Introduction}

Stent dislodgment is uncommon complication of percutaneous coronary procedures (PCI), mainly due to the improvements in stent design with better diverability, flexibility, and near universal fabrication of premounted stents, as well as increased overall physician/operator knowledge and awareness in performing complex and challenging PCI [1]. Nevertheless, when it occurs it presents a challenge to even most experienced operators, because it is often associated with significant morbidity, including systemic or coronary embolization, acute myocardial infarction (AMI), emergency coronary artery bypass graft surgery $(\mathrm{CABG})$, or even death $[2,3]$. Here, we present a case of stent dislodgment in left main (LM) with subsequent retrieval of loose stent and unintentional extraction of previously implanted stent causing intimal tearing of distal LM and ostial LAD.

Fifty-nine years old female patient was admitted for acute ST elevation myocardial infarction to the catheterization laboratory two and a half hours after the onset of chest pain. Patient was hemodinamicaly stabile, Killip class 1 at admission. She had no previous history of heart disease, with smoking as the only coronary artery disease (CAD) risk factor. Coronary angiography

revealed three vessel CAD with chronically occluded right coronary artery (RCA), severely calcified and diseased proximal segment of circumflex artery (Cx) and culprit occlusion of ostial left anterior descending artery (LAD) with intraluminal thrombus (Figure 1A \& 1B).

At that time, primary PCI of the ostial LAD was performed, with previous thrombus aspiration using Export AP catheter $6 \mathrm{~F}$ (Medtronic, Minneapolis, Minnesota, USA), and final implantation of Resolute Integrity stent $3.5 \times 15 \mathrm{~mm}$ at 20atm (Medtronic Minneapolis, Minnesota, USA) in ostial segment of LAD with simultaneous protection of ostial $\mathrm{Cx}$ with non-compliant balloon inflation of Sprinter NC 3.0 x15mm (Medtronic, Minneapolis, Minnesota, USA) up to 12atm (Figure 1C). Final angio showed good result in ostial/proximal LAD with TIMI 3 flow in the infarct artery, and minor carina shift in ostial Cx (Figure 1D).

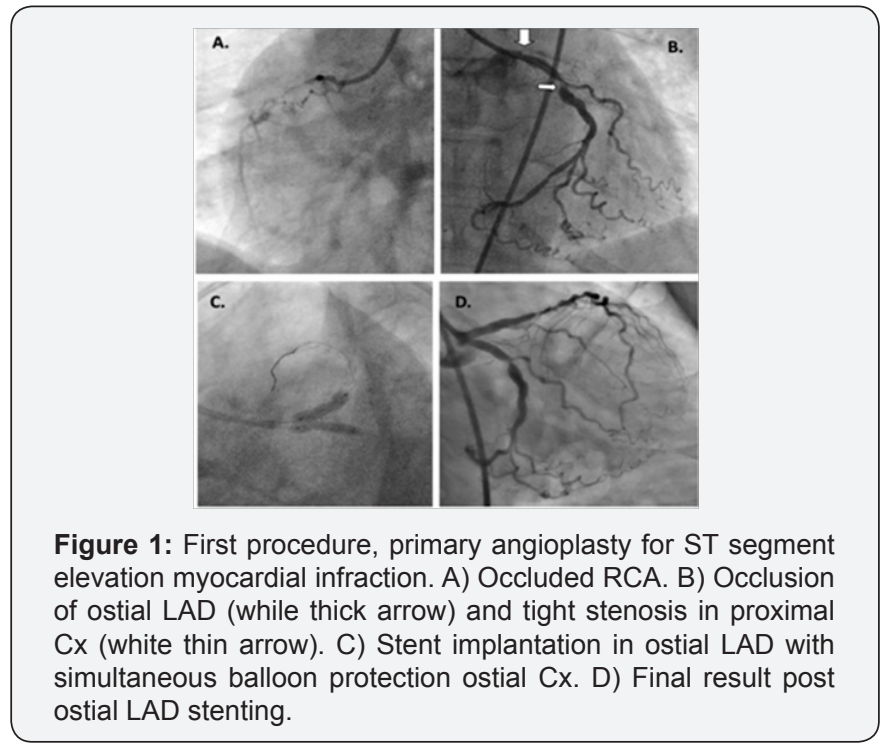

After opening of occluded LAD, severe stenosis of the mid portion of the artery was appreciated, and after recovery considered for elective PCI together with proximal Cx stenosis. Complete ST resolution was achieved in anterior leads and patient was pain free while being transferred to coronary care unit (CCU). The day after cardiac enzymes were elevated (CK 
845U/L, CK MB 92U/L, troponin I $16.79 \mu \mathrm{g} / \mathrm{L}$ ) and the patient was feeling well.

Elective PCI was scheduled in 7 days since patient made a good recovery in CCU without sings of heart failure and taking into account the severity of the stenoses in proximal $\mathrm{Cx}$ and mid LAD and the risk of adverse events by prolonging the revascularization. The PCI procedure was approved by the Heart Team of our institution, and the patient provided written informed consent for the PCI procedure. We decided to treat the proximal Cx first. 7F 4.0 Launcher guide catheter (Medtronic, Minneapolis, Minnesota, USA) was used and after easy positioning, floppy wire placement in the distal $\mathrm{Cx}$, predilatation of the lesion with compliant balloon Sprinter RX 2.5x15 at 10atm, bare metal stent Liberte $4 \times 18 \mathrm{~mm}$ (Boston Scientific, Natick, MA, USA) was implanted at 18atm.

Postdilatation was done with non-compliant balloon NC Sprinter $4 \times 12 \mathrm{~mm}$ (Medtronic, Minneapolis, Minnesota, USA) at 22atm accomplishing good final result despite severe calcifications (Figure 2A). We then decided to treat the long and calcified mid LAD lesion (Figure 2B). Soft tip guide wire was placed in distal LAD without difficulties passing through the stent in ostial LAD, implanted 7 days ago, and balloon predilatation of mid and proximal portion of LAD was performed using compliant balloon Sprinter RX 2.0x20mm at 14atm.

Attempts to pass the bare metal stent Liberte $2.75 \times 28 \mathrm{~mm}$ (Boston Sceintific, Natick, MA, USA) in order to cover the whole lesion were unsuccessful and further persistence resulted in dislodgment of the stent in the left main (LM) during attempts to pull-back stent in guide catheter in order to proceed with further predilatation of the calcified lesion, with simultaneous loss of distal wire position in LAD and more importantly within stent carrier lumen (Figure 2C). In order to keep the vessel open, the other soft wire was placed in the distal LAD next to the dislodged stent with considerable difficulties. At this point, the patient was relatively stable, with some chest pain but no significant ECG changes.

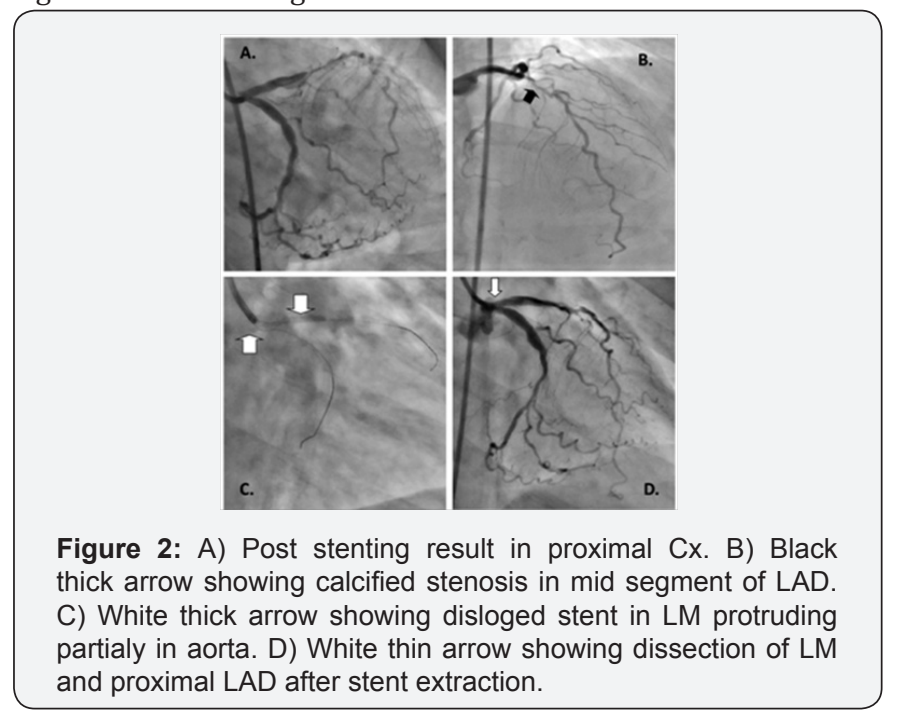

We then attempted to retrieve the stent with Lasso catheter (Balton, Warszawa, Poland) and finally succeed but at the cost of pulling back the coronary wires into the guiding catheter due to inability to catch the stent protruding in the aorta with the coronary wires next to it. However, the firm resistance and vigorous force applied to pull the stent back resulted in brakeage of catheter loop. We then decided to use stronger device Amplatz Goose Neck Snare Kit (ev3, Plymouth, MN, USA) and after few attempts we were able to catch the proximal portion of dislodged stent that protruded through LM in aorta. After strengthful pulling, finally applied tension resulted in retrieval of stent in guide catheter and safe removal out of the system, with a loose of distal wire position due to abrupt jump-back reaction of the whole system. Examination of retrieved device revealed that another stent, until that moment fully deployed in ostial LAD, was mounted as well in distorted fashion alongside the dislodged undeployed stent (Figure 3A \& 3B).

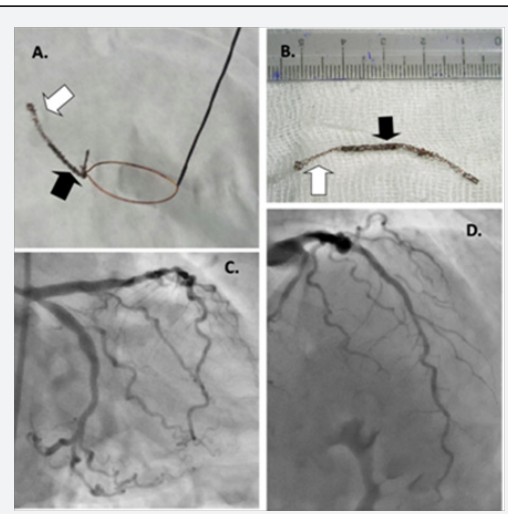

Figure 3: A) Snare Goose Neck with retrieved stents. B) Two retrieved stents, extracted one marked with thick black arrow and dislodged marked with thick black arrow mounted together. C \& D) Final results in two angiographic views.

Control angio revealed non-obstructive dissection of LM and proximal LAD due to initima avulsion and soon after patient started complaining of chest pain but without significant ECG changes (Figure 2D). Immediately, we proceeded with PCI of LAD and after predilatation with Sprinter $2.5 \times 20 \mathrm{~mm}$ balloon at $14 \mathrm{~atm}$ we finally implanted two BMS in mid and proximal LAD (Liberte $2.75 \times 20 \mathrm{~mm}$ and $3.0 \times 20 \mathrm{~mm}$; Boston Sceintific, Natick, MA, USA).

LM dissection was treated with drug eluting stent implantation Resolute Integrity 4.0 x $18 \mathrm{~mm}$ (Medtronic, Minneapolis, Minnesota, USA) at 12-14atm across the ostium of side branch, $\mathrm{Cx}$, in provisional bifurcation technique. Final result showed no residual dissection and excellent overall angiographic result without need for final kissing dilatation (Figure 3C \& D). After second procedure patient had no enzyme elevation and was discharged home after 2 days in good health.

\section{Discussion}

We have demonstrated that snare devices can be used with success to safely retrieve dislodged stent and prevent 
urgent surgical extraction. However, extreme caution must be expressed when this is happening through or in vicinity of recently implanted stents. Various devices and techniques, like low-profile balloon catheters, gooseneck snares, myocardial biopsy forceps, baskets, tip-deflecting wires, pincher devices and multipurpose baskets, have been used for capturing and safely removing loose parts by percutaneous technique [4]. Some of these approaches demand that the carrier guide wire remained intact, but when situations like this occur when medical device is completely loose due to lost of wire distal position, snares are reportedly most successfully used devices $[5,6]$.

There have been just a few reports in literature of simultaneous removal of dislodged and previously implanted stent with snare device $[7,8]$. In both cases, previously implanted stent was at aorto-ostial junction with protruding struts into aorta. These protruding struts were caught by loop of the snare simultaneously with the dislodged stent. In our case, extracted stent was implanted in ostial LAD and could not be accessed directly by snare, meaning that strut-to-strut interlock between dislodged and previously implanted stent was firm enough to pull back both stents when strenuous traction was applied.

We have to emphasize few points as opportunities where we could have acted in different manner that might prevent the complication. First and most importantly, small compliant balloons do not offer enough space for traction-free stent delivery, especially in case as this one, where unfavourable anatomy is present and lesion is distal to recently implanted and un-endothelialized stent. Second, although inflation pressure for the stent during primary PCI was relatively high (20atm), intravascular ultrasound (IVUS) could have given us more information in this particular situation about implanted stent geometry, under-deployment or possible strut intraluminal protrusion due to the fact that the stent was implanted simultaneously with balloon inflation that could lead to proximal deformation.

Third, every attempt should be made not to lose the distal wire position in order to prevent or quickly resolve unwanted abrupt vessel closure that can occur after endothelial injury. One way to achieve that might be to push the wire deeply forward until backward wire loop is made in aorta, that would allow snare to approach and grasp the dislodged stent without interference, and also allow backward motion during catheter and whole system instant bounce due to accumulated tension. And last but not least, despite the fact that we were aware after wire brakeage of thinner loose device occurred that the dislodged stent was apparently firmly stuck within the vessel, we applied more tension using higher traction and thicker-wire snare.

Extraction of previously implanted stents is a rare complication of PCI. Good preoperative strategy with optimal lesion preparation is essential for preventing these events. In our case we demonstrated that complicated bailout procedures such as snare extraction of intravascular objects can be done, but when performed in vicinity or previously implanted stents, extreme caution must be taken.

\section{References}

1. Eggebrecht H, Haude M, von Birgelen C, Oldenburg O, Baumgart D, et al. (2000) Nonsurgical retrieval of embolized coronary stents. Catheter Cardiovasc Interv 51(4): 432-440.

2. Bolte J, Neumann U, Pfafferott C, Vogt A, Engel HJ, et al. (2001) Incidence, management, and outcome of stent loss during intracoronary stenting. Am J Cardiol 88(5): 565-567.

3. Brilakis ES, Best PJ, Elesber AA, Barsness GW, Lennon RJ, et al. (2005) Incidence, retrieval methods, and outcomes of stent loss during percutaneous coronary intervention: a large single-center experience. Catheter Cardiovasc Interv 66(3): 333-340.

4. Koseoglu K, Parildar M, Oran I, Memis A (2004) Retrieval of intravascular foreign bodies with goose neck snare. Eur J Radiol 49(3): 281-285.

5. Dinkel HP, Muhm M, Exadaktylos AK, Hoppe H, Triller J (2002) Emergency percutaneous retrieval of a silicone port catheter fragment in pinch-off syndrome by means of an Amplatz gooseneck snare. Emerg Radiol 9(3): 165-168.

6. Savage C, Ozkan OS, Walser EM, Wang D, Zwischenberger JB (2003) Percutaneous retrieval of chronic intravascular foreign bodies. Cardiovasc Intervent Radiol 26(5): 440-442.

7. Kim JW, Kim W (2012) Unintentional extraction of a coronary stent deployed two months prior during a dislodged left main stent retrieval. Int J Cardiol 156(2): e45-e48.

8. Cheema JK, Shroff AR, Vidovich MI (2013) Unintentional extraction of an endothelialized bare metal stent. Cardiovasc Revasc Med 14(3): 187-190.

\begin{tabular}{|l|}
\hline \multicolumn{1}{|c|}{ Your next submission with Juniper Publishers } \\
will reach you the below assets \\
- Quality Editorial service \\
- Swift Peer Review \\
- Reprints availability \\
- E-prints Service \\
- Manuscript Podcast for convenient understanding \\
- Global attainment for your research \\
- Manuscript accessibility in different formats \\
( Pdf, E-pub, Full Text, Audio) \\
- Unceasing customer service \\
Track the below URL for one-step submission \\
https://juniperpublishers.com/online-submission.php \\
\hline
\end{tabular}

